\title{
Time-Course Study of Gastric Damages in Rats by Anti-Inflammatory Drugs Using a Gastroscope and Its Quantification
}

\author{
Akira FUJII, Noboru KUBOYAMA, Sumi KOBAYASHI, \\ Yoshikazu NAMIKI and Toyoyuki TAMURA \\ Department of Pharmacology. Nihon University School of Dentistry at Matsudo. \\ 2-870-1 Sakaecho-Nishi, Matsudo, Chiba 271. Japan
}

Accepted July 12,1988

\begin{abstract}
Time-course studies on gastric damages in rats caused by nonsteroidal anti-inflammatory drugs (NSAIDs) were performed using a gastroscope, and the readings were quantified to obtain the Congestion-Hemorrhage Index (CHI) for evaluating the potencies of the damaging properties of NSAID. The correlation between $\mathrm{CHI}$ and Ulcer Index (UI), the quantified value obtained by the conventional methods, was highly significant at 6 and $24 \mathrm{hr}$ after forced oral administration of NSAID. The peak CHls of aspirin $(300 \mathrm{mg} / \mathrm{kg})$, indomethacin $(60 \mathrm{mg} /$ $\mathrm{kg}$ ), mefenamic acid $(300 \mathrm{mg} / \mathrm{kg}$ ) and fenoprofen calcium $(300 \mathrm{mg} / \mathrm{kg}$ ) appeared approximately $24 \mathrm{hr}$ after a single forced oral administration of drugs. Thus, it was suggested that an observation at $24 \mathrm{hr}$ in addition to one at 6 to $7 \mathrm{hr}$ might be necessary for the examination of damaged gastric mucosa. Under the present experimental conditions, fenoprofen calcium caused the greatest damages on gastric mucosa among the four NSAIDs. Mefenamic acid showed the least damaging potency on gastric mucosa, having a smaller $\mathrm{CHI}$ than that of aspirin. Indomethacin possessed a stronger damaging property than aspirin.
\end{abstract}

Nonsteroidal anti-inflammatory drugs (NSAIDs), such as aspirin, indomethacin, possess excellent analgesic, antipyretic and anti-inflammatory effects (1-4) and are widely accepted in daily practice $(4,5)$. However, as to their deleterious effects, these drugs also induce erosion and ulcers on gastrointestinal mucosa $(4,6-9)$.

The common characteristic of these drugs is their ability to inhibit cyclooxygenase. which results in the inhibition of prostaglandin (PG) synthesis (10-12). As a cytoprotection factor. $P G$ plays an important role in the prevention of ulceration. NSAIDs also readily cause gastrointestinal damage in experimental animals, thus one can use NSAIDs to induce experimental ulceration for the purpose of studying of the etiology of gastrointestinal ulceration (7, 8, 13-18). However, only a few reports have dealt with the detailed timecourse of changes in the gastric mucosa after drug administration such as the initiation and progression of erosion and ulcer, repair and finally the disappearance of erosion and ulcer. Anderson (19) reported the incidence of animals with gastric damage and the mean number of mucosal erosions at 15, 30, 60, 120 and $180 \mathrm{~min}$, and 24 and 36 hr after the administration of ball-milled aspirin at 100 or $500 \mathrm{mg} / \mathrm{kg}$ to fasted guinea pigs. They demonstrated that the majority of lesions were established within 1 to $2 \mathrm{hr}$ of dosing. and there was little subsequent change in the stomachs at $3 \mathrm{hr}$; furthermore, there was no hemorrhage or scarring at 24 or $36 \mathrm{hr}$. Seegars et al. (20) reported the erosive activity of aspirin $(250 \mathrm{mg} / \mathrm{kg})$ in male rats at $0.5,1.5$. 4. 8 and $17 \mathrm{hr}$ after administration; they demonstrated that small erosion-foculi $(<2$ $\mathrm{mm}$ ) appeared in the glandular mucosa within $1.5 \mathrm{hr}$ after aspirin treatment, and the maximal erosion-response was reached after 
$8 \mathrm{hr}$.

The experimental ulcer caused by NSAID using animals had been applied extensively in the preclinical examinations for the screening of drugs for the treatment of peptic ulcer. In such cases, most of the reports have evaluated the effectiveness by use of the ulcer index $(U \mid)$ obtained at less than $7 \mathrm{hr}$ after the administration of NSAID $(13,21$, 22). Studies to determine if determining the index at less than $7 \mathrm{hr}$ is suitable for these experiments has also not been made.

The present investigation was employed a gastroscope to observe the changes of gastric mucosa during a 5 day period beginning from immediately after the administration of NSAID to complete healing of the ulcer. The degree of damage determined by gastroscopic observation was quantified to obtain a reliable method for the evaluation of drugs. A comparison between the present new evaluation and the conventional method was also done by obtaining $\mathrm{CHIs}$ and U/s at $6 \mathrm{hr}$ and $24 \mathrm{hr}$ after administration of NSAIDs such as aspirin, indomethacin, mefenamic acid and fenoprofen calcium.

\section{Materials and Methods}

Animals: Slc Sprague-Dawley strain male rats, 5 weeks old, were purchased from the Shizuoka Agricultural Cooperative Association for Laboratory Animals. They were kept at a room temperature of $23 \pm 1{ }^{\circ} \mathrm{C}$. humidity of $60 \pm 10 \%$, and lighting for $12 \mathrm{hr}$ a day (7:0019:00). Rats were maintained on commercial rat chow (MF. Oriental Yeast Co., Japan) and purified water (distilled water) ad libitum for the duration of the study. Before the experiments, the rats were starved for $24 \mathrm{hr}$ but allowed free access to water.

Drugs: Aspirin (Lot No. F121) was purchased from Tsukishima Pharmaceutical Co., and indomethacin (Lot No. PEP7180) was purchased from Wako Pure Chemical Industries, Ltd. Mefenamic acid (Lot No. M51129) and fenoprofen calcium were gifts from Meiji Seika Kaisha, Ltd and Yamanouchi Pharmaceutical Co., Ltd., respectively. These drugs were suspended into $1 \%$ carboxymethyl cellulose (CMC) and given by stomach sonde. The doses of aspirin, indomethacin. mefenamic acid and fenoprofen calcium were
$300,60,300$ and $300 \mathrm{mg} / \mathrm{kg}$, respectively.

A gastroscope: Endoscope (FBS-3.5TH $3.5 \mathrm{~mm}^{*}$. Machida, Japan) equipped with an angle system, gas and water inlets, a light source (RM-300T, Machida, Japan), and a camera (Kouwa Scopecamera SQ-16. Kouwa, Japan) was used. An arthroscope (No. 54736, $1.8 \mathrm{~mm}^{\circ}$. Machida, Japan) equipped with a light source ( $\mathrm{RH}-150 \mathrm{II}$ Machida, Japan) was used for the insertion of esophagus cannula.

Observation of gastric mucosa through the gastroscope: Twenty-five rats were starved for $24 \mathrm{hr}$, but allowed free access to water. and then divided into 5 groups ( 5 rats/group) Groups 1 to 4 were orally given aspirin, indomethacin. mefenamic acid and fenoprofen calcium, respectively. The fifth group was a control and given the same volume 10.5 $\mathrm{ml})$ of CMC solution. Rats were anesthesized with a single i.v. administration through the jugular vein of $20 \mathrm{mg} / \mathrm{kg}$ of pentobarbital sodium (Nembutal. Abbott) $30 \mathrm{~min}$ after forced oral administration of NSAID, and then they were fixed supine on a CFK operating table. Using the arthroscope, a cannula made of a polyethylene tube $(1.5$ $\mathrm{mm}^{\circ}$ ) was inserted into the esophagus. The fiberscope, lubricated with lidocaine jelly (Xylocaine, Fujisawa), was then inserted approx. $12 \mathrm{~cm}$ until the top reached to the gastropyloric region. The changes of damaged gastric mucosa, congestion and hemorrhage were observed at $0.5,1,3,6,9,12,18,24$, $36,48,72,96$ and $120 \mathrm{hr}$ after administration of the NSAID. In order to evaluate the degree of change the damages were evaluated by the following point system: point redness by congestion, 1: point hemorrhage, 2: linear redness, 2; minor linear hemorrhage. 3; mild linear hemorrhage, 4; severe linear hemorrhage, 5: and the total score/stomach was termed the Congestion-Hemorrhage Index (CHI)

Determination of ulcer index (UI) by the conventional method: Rats were treated in the same manner as above and then anesthesized with ether at 6 and $24 \mathrm{hr}$ after the administration of NSAID. Subsequently, their stomachs were extracted. After treatment with buffered formalin for $20 \mathrm{~min}$, the stomach was incised along the greater 
curvature, and then the entire area was examined for the presence of mucosal lesions. The length $(\mathrm{mm})$ of each necrotic lesion was measured, summed per stomach. and the value was used as the UI (23).

Statistics: The data are expressed as the mean \pm S.D. in the text and illustrations, and the significance of the differences between mean values was obtained by Student's $t$ test for parametric data and Welch's $t$-test for nonparametric data.

\section{Results}

Time-course change of gastric mucosa damaged by NSAID (observation with a gastroscope): Time-course changes of gastric mucosa damaged by NSAID, observed with a gastroscope and expressed by $\mathrm{CHI}$, are shown in Fig. 1.

Aspirin $(300 \mathrm{mg} / \mathrm{kg})$ : A few points of congestion and hemorrhage were seen in the ragstrnoy, nir reginn at 30 min after. a. forced oral administration of aspirin; and several points were observed at 60 min after the treatment, of which the CHIs were $2.2 \pm$ 0.8 and $8.4+2.5$, respectively. The damage on gastric mucosa proceeded thereafter, and $\mathrm{CHl}$ at $3 \mathrm{hr}$ was $13.4 \pm 3.6$. No particular

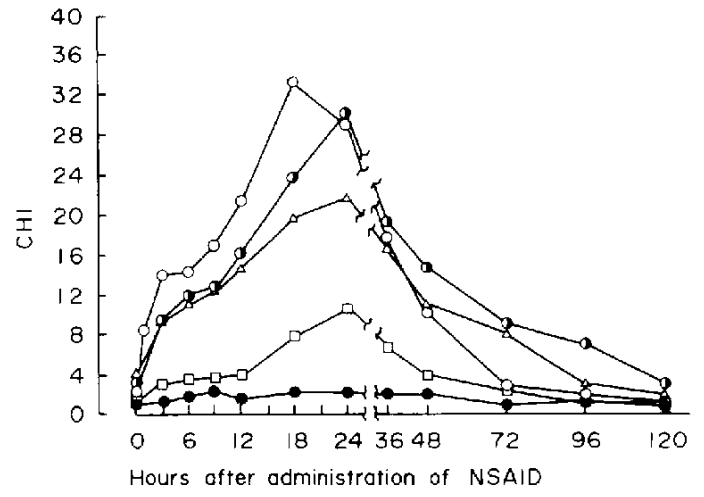

Fig. 1. Time-course change of rat gastric mucosa. observed with ar endoscope and expressed as the Congestion-Hemorhage Index (CHI), damagea by NSAiDS, aspirin, indomethacin, mefenamic acid and feroprofen calcium. Observation was started immediately after administration of NSAID. - - yaspirin ( $300 \mathrm{mg} / \mathrm{kg} . \mathrm{n}=5$ ). .- $\triangle-$ : indomethacin $(60$ $\mathrm{mg} / \mathrm{kg}, \mathrm{n}=5),--\Pi$...: mefenamic acid $(300 \mathrm{mg} / \mathrm{kg}$. $n=5)$. - - fenoprofen calcium (300 mg/kg. $n-5)$. - control (intaci animal, $n-5)$ change was seen during 3 to $6 \mathrm{hr}$, and then the $\mathrm{CHI}$ again progressed to reach the maximum $(33.4 \pm 4.8)$ at $18 \mathrm{hr}$ after the treatment, with clear point- and linear hemorrhage. Healing started after the peak $(18 \mathrm{hr}$ ), and CHIs at 24 and $36 \mathrm{hr}$ were $29.2 \pm$ 5.8 and $17.8 \pm 4.0$, respectively. No hemorrhage could be seen at $72 \mathrm{hr}$ after the treatment; the $\mathrm{CH}$ l value was $2.8 \pm 0.8$.

Indomethacin $(60 \mathrm{mg} / \mathrm{kg})$ : No specific change was seen 30 min after a forced oral administration of indomethacin, and slight changes were observed during the next $3 \mathrm{hr}$. A gradual progress of damage was then seen around the greater curvature, it reached the maximum $\mathrm{CHI}$ of $22.4 \pm 4.1$ at $24 \mathrm{hr}$. Healing started after the peak ( $24 \mathrm{hr}$ ), and $\mathrm{CHIs}$ at $48 \mathrm{hr}$ and $72 \mathrm{hr}$ were $11.4 \pm 2.3$ and $8.4 \pm 2.6$. respectively. Disappearance of hemorrhage was noticed at $96 \mathrm{hr}$ after the treatment.

Mefenamic acid $(300 \mathrm{mg} / \mathrm{kg})$ : No specific damagena, ngstric mucosawnasuceen, turinos $9 \mathrm{hr}$ after a forced oral administration of mefenamic acid. Point hemorrhage started to appear at $12 \mathrm{hr}$ after the treatment and hemorrhage at $18 \mathrm{hr}$, reaching the maximum $\mathrm{CHI}$ of $11.0 \pm 2.7$ at $24 \mathrm{hr}$ after the treatment. Hemorrhage disappeared by $72 \mathrm{hr}$ after the treatment. Melena was seen at $24 \mathrm{hr}$ to $72 \mathrm{hr}$ after the treatment.

Fenoprofen calcium (300 $\mathrm{mg} / \mathrm{kg})$ : No specific damage on gastric mucosa was observed for the first $1 \mathrm{hr}$ after forced oral administration of fenoprofen calcium. However, erosion started to be seen $3 \mathrm{hr}$ after the treatment; and with further lapse of time. severe linear hemorhage was observed around the greater curvature. The peak $\mathrm{CHI}$ of $30.2=5.7$ was found at $24 \mathrm{hr}$ after the treatment. $\mathrm{CHI}$ values then decreased and were $10.2 \pm 3.4$ and $6.8 \pm 3.0$ at $72 \mathrm{hr}$ and 96 hr after the treatment, respectively. It took $120 \mathrm{hr}$ for the complete disappearance of hemorrhage. Melena was seen 24 hr to 72 hr after the treatment.

Determination of ulcer indexes obtained at $6 \mathrm{hr}$ and $24 \mathrm{hr}$ after NSAID administration: UIs of the stomach that were obtained at 6 $\mathrm{hr}$ and $24 \mathrm{hr}$ after forced oral administrations of aspirin, indomethacin, mefenamic acid and fenoprofen calcium are summarized in Fig. 2. Mean Uls at $6 \mathrm{hr}$ and $24 \mathrm{hr}$ after the 
treatment of aspirin $(300 \mathrm{mg} / \mathrm{kg})$ were $8.6 \pm$ 3.9 and $20.8 \pm 5.3$, respectively. In the case of indomethacin $(60 \mathrm{mg} / \mathrm{kg})$. Uls were $5.2 \pm$ 2.2 and $14.6 \pm 5.7$. respectively. In both cases, spot and linear hemorrhages were seen in the gastropyloric region at $24 \mathrm{hr}$ after the treatments. Mean Uls at $6 \mathrm{hr}$ and $24 \mathrm{hr}$ after the treatment of mefenamic acid (300 $\mathrm{mg} / \mathrm{kg}$ ) were $2.0 \pm 1.5$ and $8.6 \pm 3.7$.

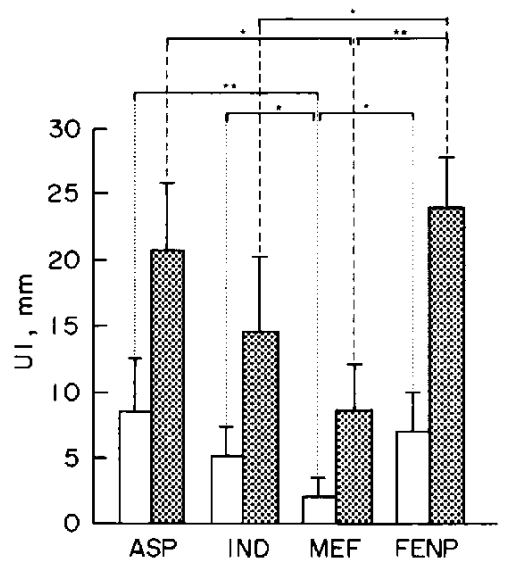

Fig. 2. Comparative damaging potencies of NSAIDs. Ulcer Index (Ui) at gastric mucosa by naked eye observation at $6 \mathrm{hr}$ and $24 \mathrm{hr}$ after the treatment. ASP: Aspirin ( $300 \mathrm{mg} / \mathrm{kg}, \mathrm{n}=5$ ). IND Indomethacin $(60 \mathrm{mg} / \mathrm{kg}, \mathrm{n}=5)$. MEF: Mefenamic acid $(300 \mathrm{mg} / \mathrm{kg}, \mathrm{n}=5)$. FENP: Fenoprofen calcium (300 mg/kg, n=5). $\square$ : 6 hr. S.D. *: Po<0.05.**: Po<0.01. respectively. The damage was mostly point hemorrhage and was found around the pyrolic region, and the damage was the lowest among the four NSAIDs. In the case of fenoprofen calcium $(300 \mathrm{mg} / \mathrm{kg}$ ). Uls at $6 \mathrm{hr}$ and $24 \mathrm{hr}$ after the treatment were $7.0 \pm$ 2.9 and $23.8 \pm 3.8$, respectively. Significant differences were found between aspirin and mefenamic acid $\left(P_{0}=0.0077\right)$, indomethacin and mefenamic acid $\left(P_{0}=0.0276\right)$ and mefenamic acid and fenoprofen calcium $\left(P_{0}=\right.$ 0.0109 ), at $6 \mathrm{hr}$, and between aspirin and mefenamic acid $\left(P_{0}=0.0129\right)$, indomethacin and fenoprofen calcium $\left(P_{o}=0.0170\right)$ and mefenamic acid and fenoprofen calcium $\left(P_{0}=0.0002\right)$, at $24 \mathrm{hr}$.

Comparison between $\mathrm{CHI}$ and $\mathrm{UI}$ of stomach: The comparison between respective mean $\mathrm{CHI}$ and $\mathrm{UI}$ on damages caused by each NSAID on gastric mucosa at $6 \mathrm{hr}$ and $24 \mathrm{hr}$ after the treatments are shown in Fig. 3. The correlation coefficient $(r)$ at $6 \mathrm{hr}$ and $24 \mathrm{hr}$ after the treatments were 0.954 and 0.979 , respectively, both of which were significant $\left(P_{\circ}<0.005\right)$.

\section{Discussion}

The present novel approach, the $\mathrm{CHI}$ method. was found to be comparable to the conventional method, UI method, in which six to $7 \mathrm{hr}$ after the administration of drugs. the rats were sacrificed and their damaged

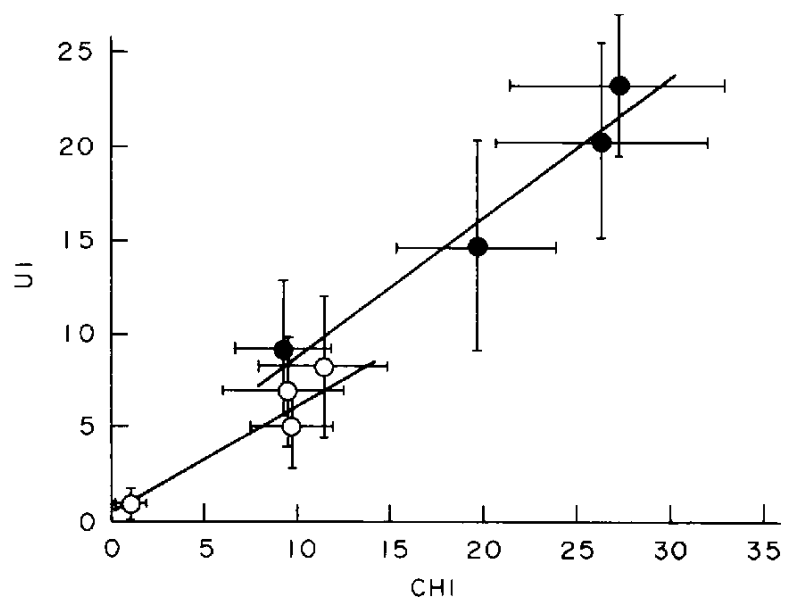

Fig. 3. Correlation between endoscopic observation ( $\mathrm{CHI}$ ) and naked eye observation (Ui) on lesions of rat gastric mucosa caused by NSAID. $O: 6 \mathrm{hr}$, (UI) $=0.584(\mathrm{CHI})+0.886\left(\mathrm{r}=0.953, \mathrm{Po}_{\mathrm{o}}<0.05\right)$, $24 \mathrm{hr},(\mathrm{UI})=0.747(\mathrm{CH})+1.486\left(r=0.979, P_{0}<0.005\right)$. Horizontal and vertical bars: Mean $\pm S . D .(n=5)$. 
gastric mucosa were examined quantitatively. As shown in Fig. 3, the correlation between the present approach $(\mathrm{CHI})$ and the conventional method (UI) was highly significant.

The present approach has several merits compared to the conventional method. First of all, there was no need to sacrifice animals, this enables one to reduce the number of animals for the experiment. This fact must be also considered with respect to economics and the animal's welfare. Since time-course observation of damaged gastric mucosa was possible, the maximum damage was found approx. $24 \mathrm{hr}$ after administration of NSAIDs (Fig. 1). Thus, in addition to an observation at 6 to $7 \mathrm{hr}$, it might also be necessary to examine the animals at $24 \mathrm{hr}$ after the treatment in the conventional method.

On the other hand, the present approach might require greater skills for animal experimentation and reliable reading of the endoscope. Since the animal was not sacrificed during the experimental period, it was not possible to identify the precise damaging property, which might be obtainable through histo-pathological examination.

Although a conclusive comparison could not be made. our data suggests the following order of relative damaging potency on the gastric mucosa among the NSAIDs tested under the present experimental conditions: fenoprofen calcium $>$ aspirin $>$ indomethacin $>$ mefenamic acid. Ridolfo et al. (24) reported that the loss of blood in human feces follow ing an oral dose of fenoprofen calcium (400 $\mathrm{mg}$ and $600 \mathrm{mg}$ acid equivalent) every $6 \mathrm{hr}$ for 4 days was significantly less than that following administration of an aspirin (650 $\mathrm{mg}$ and $1000 \mathrm{mg}$ ) preparation. The difference of the results obtained in the present study and the data of Ridolfo et al. (24) might be due to a difference in the doses employed. In the present study, fenoprofen calcium, which is poorly soluble in water, was administered in the form of a $1 \%$ CMC suspension and undissolved crystals might directly affect the gastric mucosa, in the same manner as aspirin. On the other hand, in the human study (24), fenoprofen calcium might dissolve completely, so that it would not have great effects on the gastric mucosa. The dose of indomethacin used in the present experiment is three times the clinical dosage compared to the other NSAIDs. Therefore, the damaging potency on gastric mucosa in a clinical study might be lower than the present result. Mefenamic acid has also been reported to possess a weak damaging property on gastric mucosa (25, 26).

In conclusion, the approach described in the present study might be acceptable for the evaluation of gastric damage; it has the merit of reducing the number of experimental animals required. which is advantageous with regards to economics and animal welfare. and it is a good method because it allows a time course study to be performed in single animals.

Acknowledgment: This research was supported in part by a Suzuki Grant from the Nihon University School of Dentistry at Matsudo.

\section{References}

1 Winter, C.A., Risley, E.A. and Nuss, G.W.: Antiinfiammatory and antipyretic activities of indomethacin. 1-(p-chlorobenzoyl)-5-methoxy -2 methylindole-3-acetic acid. J. Pharmacol. Exp. Ther. 141, 369-376 (1963)

2 Winder, C.V., Wax, J., Scotti, L., Scherrer, R.A., Jones, E.M. and Short, F.W.: Anti-inflammatory. antipyretic and antinociceptive properties of $\mathrm{N}$ (2,3-xylyl)anthranilic acid (mefenamic acid). J. Pharmacol. Exp. Ther. 138, 405-413 (1962)

3 Fujimura, H., Tsurumi, K., Hiramatsu, Y. and Tamura, $Y$ : Anti-inflammatory, analgesic and antipyretic activities of fenoprofen calcium. Pharmacometrics 19, 329-347 (1980) (Abs. in English)

4 Flower, R.J.. Moncada, S. and Vane, J.R.: Drug therapy of inflammation. analgesic-antipyretics and anti-inflammatory agents: Drugs employed in the treatment of gout. In The Pharmacological Basis of Therapeutics, Edited by Gilman, A.G. Goodman, L.S., Rall, T.W. and Murad, F., p. 674715. Macmillan Publishing Company. New York (1985)

5 Cass, L.G. and Frederik, W.S: Experiments in relief of clinical pain with $\mathbb{N}-(2,3-x y l y)$ anthranilic acid (Cl-473, mefenamic acid). J. Pharmacol. Exp. Ther. 139, 172-176 (1963)

6 Overholt, B.F. and Pollard, H.M.: Acetylsalicylic acid and ionic fluxes across the gastric mucosa of man. Gastroenterology 54, 538-542 (1968)

7 Brodie, D.A. and Chase, B.J.: Role of gastric acid in aspirin-induced gastric irritation in the rat. 
Gastroenterology 53,604-610 (1967)

8 Davenport, H.W.: Gastric mucosal injury by fatty and acetylsalicylic acid. Gastroenterology 46 . 245-253 (1964)

9 Wolfe, J.A., Plotzker, R., Safina, F.J., Ross, M., Popky, G. and Rubin, W.: Gastritis, duodenitis. and bleeding duodenal ulcer following mefenamic acid therapy. Arch. Intern. Med. 136, 923925 (1976)

10 Ferreira, S.H., Moncada, S. and Vane, J.R.: Indomethacin and aspirin abolish prostaglandin release from the spleen. Nature 231, 237-239 (1971)

11 Arakawa, T., Nakamura, H., Chono, S., Yamada, $H$. and Kobayashi, K.: Prostaglandin $E_{2}$ in the rat gastric mucosa - Establishment of assay procedure and effects of non-steroidal antinflammatory compounds-. Japari. J. Gastroeriterol. 77, 1052-1059 (1980) (Abs. in English)

12 Robert, A., Nezamis, J.E., Lancaster, C. and Hanchar, A.J.: Cytoprotection by prostaglandins in rats. Prevention of gastric necrosis produced by alcohol, $\mathrm{HCl}, \mathrm{NaOH}$, hypertonic $\mathrm{NaCl}$, and thermal injury. Gastroenterology 77, 433-443 (1979)

13 Takeuchi, K., Nobuhara, Y. and Okabe, S.: Models of peptic ulcer. Pharmacia Review No. 13. p. 53-64. Japan. Pharm. Soc., Tokyo (1984) (in Japanese)

14 Okabe, S., Takeuchi, S., Nakamura, K. and Takagi, K.: Pathogenesis of gastric lesions induced by aspirin in the pylorus-ligated rat. Japan. J. Pharmacoi. 24, 363-371 (1974)

15 Takeuchi, K., Furukawa, O., Tanaka, H., Nishiwaki, $H$. and Okabe, S.: Impairment of acidneutralizing capacity and lesion formation in the rat duodenum during hemorrhagic shock: Comparative study with indomethacin. Japan. J. Pharmacol. 44, 163-170 (1987)

16 Takeuchi, K., Nishiwaki, H., Ishihara, Y. and Okabe, S.: Roles of gastric motility changes in cytoprotection induced by acetazolamide and cysteamine in rats. Japan. J. Pharmacol. 44, 269-281 (1987)

17 Takeuchi, K., Nishiwaki, H., Furukawa, O. and Okabe, S.: Cytoprotective action of histamine against $0.6 \mathrm{~N} \mathrm{HCl-induced} \mathrm{gastric} \mathrm{mucosal}$ iniury in rats; Comparative study with adaptive cytoprotection induced by exogenous acid.
Japan. J. Pharmacol. 44, 335-344 (1987)

18 Furukawa, O., Nishiwaki, H., Takeuchi, K. and Okabe, S.: Effects of prostaglandin biosynthesis inhibitors and ouabain on duodenal mucosa and $\mathrm{HCO}_{3}{ }^{-}$secretion in rats. Japan. J. Pharmacol. 43, 449-453 (1987)

19 Anderson, K.W.: A study of the gastric lesions induced by aspirin in laboratory animals. Arch. Int. Pharmacodyn. Ther. 152, 379-391 (1964)

20 Seegers, A.J.M., Jager, L.P. and Van Noordwijk, D.: Effects of phenacetin, paracetamol and caffeine on the erosive activity of acetylsalicylic acid in the rat stomach: Dose-response relationships, time course of erosion development and effects on acid secretion. J. Pharm. Pharmacol. $31,840-848$ (1979)

21 Abe, $Y$, Sekiguchi, H. and Tsuru, K.: Effects of the combination of four antiulcer agents on some experimental ulcer. Pharmacometrics 27, 215227 (1984) (Abs. in English)

22 Okabe, S., Takeuchi, K., Okamoto, N. and Hirosawa, R:: Effects of 2.4-diamino-(2,5dichlorophenyl)-s-triazine malerate ( $\mathrm{MN}-1695$ ) on gastric secretion and on experimental gastric lesions in rats. (2) Comparison with other antiulcer drugs. Pharmacometrics 27, 79-86 (1984) (Abs. in English)

23 Kurebayashi, Y., Ikeda, T, and Osada, Y.: Cytoprotective action of cetrexate against $\mathrm{HCl}$ ethancl-induced gastric lesion in rats. Japan. J. Pharmacol. 46, 17-25 (1988)

24 Ridolfo, A.S., Rubin, A., Crabtree, R.E. and Gruber, C.M.: Effects of fenoprofen and aspirin on gastrointestinal microbleeding in man. Clin. Pharmacol. Ther. 14, 226-230 (1973)

25 Tsurumi, K., Hiramatsu, Y., Nozaki, M., Hayashi, M., Shibuya, T. and Fujimura, H.: Anti-inflammatory action of $\mathrm{N}$-(2,6-dichlorophenyl)-oaminophenylacetic acid (No. 1 free), sodium salt (No. $1 \mathrm{Na}$ ), $\mathrm{N}$-(2,6-dichlorophenyl)-anthranilic acid (No. 2 free) and sodium salt (No. 2 Na). I. Acute inflammation. Folia Pharmacol. Japon. 69, 299-318 (1973) (Abs. in English)

26 Sardal, J., Baillet, J., Ferrero, E. and Guzzon, V.: Étude comparative de l'action ulcérigène chez le rat de différents anti-inflammatoires non stéroidiens administrés par voie orale. Thérapie 27, $483-489$ (1972) 